\title{
A Novel Polymorphism (rs35612982) in CDKAL1 Is a Risk Factor of Type 2 Diabetes: A Case-Control Study
}

\author{
Yanni Tian ${ }^{a}$ Jing $\mathrm{Xu}^{\mathrm{a}} \quad$ Ting Huang $^{\mathrm{b}}$ Jiaqi Cui ${ }^{\mathrm{a}}$ Wei Zhang ${ }^{\mathrm{c}}$ Wei Song $^{\mathrm{a}}$ \\ Huan Chen $^{a}$ Pan Huang ${ }^{a}$ Shujun Yang ${ }^{a}$ Lu Wang $^{a}$ Xin He ${ }^{d}$ \\ Lin Wang ${ }^{\mathrm{e}}$ Wei Cui ${ }^{\mathrm{a}}$ \\ aDepartment of Endocrinology and Second Department of Geriatrics, The First Affiliated \\ Hospital of Xi'an Jiaotong University, Xi'an, China; ${ }^{b}$ Department of Nursing, the First \\ Affiliated Hospital of Xi'an Jiaotong University, Xi'an, China; 'Department of Breast Surgery, \\ the First Affiliated Hospital of Xi'an Jiaotong University Xi'an, Xi'an, China; ${ }^{d}$ Department \\ of Endocrinology, Xi'an Aerospace General Hospital, Xi'an, China; ${ }^{e}$ Department of \\ Endocrinology, Xi'an Gaoxin Hospital, Xi'an, China
}

\section{Keywords}

Type 2 diabetes $\cdot$ CDKAL1 gene $\cdot$ Polymorphisms $\cdot$ Case-control

\begin{abstract}
Background: The interaction of environmental factors and genetic factors may contribute to the risk of type 2 diabetes (T2D). We aimed to investigate whether age, gender, body mass index (BMI) and lifestyle factors have an effect on the association between the CDKAL1 polymorphisms and T2D. Methods: Eight single nucleotide polymorphisms in CDKAL1 were genotyped by Agena MassARRAY in 508 T2D patients and 503 controls. The association between the CDKAL1 polymorphisms and T2D was evaluated using logistic regression model by calculating OR and 95\% Cls. Results: We found a significant association between CDKAL1 polymorphisms (rs4712523, OR 1.42, $p=9.44 \times 10^{-5} ;$ rs4712524, OR 1.38, $p=3.28 \times 10^{-4} ;$ rs10946398, OR 1.43, $p=6.21 \times 10^{-5} ;$ rs7754840, OR 1.43, $p=6.33 \times 10^{-5} ;$ rs35612982, OR 1.34, $p=0.0010 ;$ and rs10440833, OR 1.32, $p=0.0018$ ) and T2D risk among the Han population from Northwest China. We also found that genetic variants of CDKAL1 could modify the risk of T2D that might be influenced by age, BMI and the status of smoking and drinking. Besides, rs35612982-CT ( $p=$
\end{abstract}

Y.T. and J.X. are co-first authors. 


\section{Kidney \\ Blood Pressure \\ Research}

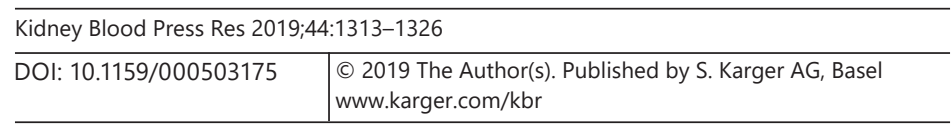

0.038) and rs10440833-AT ( $p=0.044)$ genotypes were higher insulin level. Conclusion: CDKAL1 rs35612982 (C/T) polymorphism, as a new polymorphism, was associated with the increased risk of T2D in the Han Chinese population. Moreover, the contribution of CDKAL1 polymorphisms to T2D risk seems to be associated with age, gender, BMI, smoking and drinking.

(C) 2019 The Author(s)

Published by S. Karger AG, Basel

\section{Background}

Type 2 diabetes (T2D) is a serious and common chronic metabolic disease characterized by insufficient insulin secretion leading to hyperglycaemia, and is a major life-threatening health problem throughout the world [1]. According to the World Health Organization in 2014, diabetes prevalence reached 422 million, with T2D accounting for more than $90 \%$ of these cases [2]. In China, the incidence of T2D in adults has been increasing over recent decades [3]. T2D is a complex, heterogeneous and multifactorial disorder caused by genetic and environmental factors such as obesity and unhealthy lifestyle [4]. Genetic susceptibility appears to have a crucial role in the aetiology and manifestation of the disease. Genome-wide association studies have pointed that some single nucleotide polymorphisms (SNPs) are important risk factors for T2D, which is associated with the mortality among diabetic patients $[5,6]$.

CDKAL1 gene, mapped to chromosome $6 \mathrm{p} 22.3$, encodes cyclin-dependent kinase 5 regulatory subunit-associated protein 1 (CDK5RAP1)-like 1. CDK5 is a serine/threonine protein kinase, which contributed to the glucose-dependent regulation of the insulin secretion. CDK5 plays a permissive role in the glucotoxicity, the pathophysiology of $\beta$-cell dysfunction and predisposition to T2D [7]. CDKAL1 has the protein domain similarity with CDK5RAP1, which is a negative regulator of CDK5 through the inhibition of the CDK5 activator $\mathrm{p} 35$ [8]. CDKAL1 expression in human pancreatic beta-cells [9] supports the correlation of CDKAL1- and CDK5mediated pathways. Consistently, several studies showed the association of genetic variants in CDKAL1 with the defects in proinsulin conversion and insulin response upon glucose stimulation $[10,11]$. Thus, CDKAL1 is a well-accepted pathogenesis-related key protein for T2D.

Genome-wide association studies have identified several SNPs in the CDKAL1 gene associated with T2D $[12,13]$. A recent study has reported the significant association between CDKAL1 variants and susceptibility to T2D in Caucasian and Asian but not African populations [14], indicating that the association is an ethnic difference. This necessitates the replicating the association of these variants with T2D risk in different ethnicities. Furthermore, whether there is the contribution of non-genetic factors in the association between CDKAL1 SNPs and T2D needs to be investigated.

Here, we conducted a case-control study to examine the effects of age, gender, body mass index (BMI), smoking and alcohol consumption, and CDKAL1 polymorphisms on the risk of T2D, and to explore the association of CDKAL1 SNPs with clinical characteristics among T2D patients in the Han population from Northwest China. Especially, there are no published reports assessing the role of CDKAL1 rs35612982 and rs10440833 variants in the susceptibility of T2D in a Chinese Han population.

\section{Methods}

Study Participants

A total of 508 T2D patients and 503 age- and gender-matched healthy controls with normal blood glucose levels were recruited from the First Affiliated Hospital of Xi'an Jiaotong University in this study. All recruited subjects were unrelated ethnic Han Chinese. All patients 


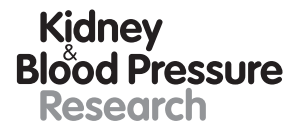

Kidney
Blood Pressure

Research \begin{tabular}{l|l}
\hline Kidney Blood Press Res 2019;44:1313-1326 \\
\hline DOI: 10.1159/000503175 & $\begin{array}{l}\text { @ 2019 The Author(s). Published by S. Karger AG, Basel } \\
\text { www.karger.com/kbr }\end{array}$ \\
\hline
\end{tabular}

Tian et al.: CDKAL1 rs35612982 Is a Risk Factor of T2D

were newly diagnosed with T2D based on fasting plasma glucose $\geq 7.0 \mathrm{mmol} / \mathrm{L}$ and/or postprandial plasma glucose $\geq 11.1 \mathrm{mmol} / \mathrm{L}$, in keeping with the WHO criteria [15]. Patients with type 1 diabetes mellitus, gestational diabetes, acute or chronic diseases of the liver, kidney, or heart or other endocrine disease, inflammatory diseases, or malignant tumours were excluded. Healthy individuals with a normal fasting glucose level and without history of T2D and other chronic diseases were recruited as controls. This case-control study was carried out with the approval of the Ethics Committee of the First Affiliated Hospital of Xi'an Jiaotong University and in accordance with the guidelines of the Declaration of Helsinki. All participants were informed about the purpose of this study and signed a written informed consent.

\section{DNA Isolation and Genotyping}

The peripheral blood ( $5 \mathrm{~mL}$ ) of all the subjects was collected in EDTA-coating tubes. The epidemiological and clinical data were collected with a questionnaire and medical records. The following data were recorded: age, gender, BMI $\left(\mathrm{kg} / \mathrm{m}^{2}\right)$, smoking habits, alcohol consumption, and clinical parameters. Genomic DNA was isolated from peripheral blood leukocytes by GoldMag DNA Purification Kit (GoldMag Co. Ltd., Xi'an, China), quantified by NanoDrop 2000 (Thermo Scientific, Waltham, MA, USA), then stored at $-20^{\circ} \mathrm{C}$ for further analysis.

Eight CDKAL1 SNPs (rs4712523, rs4712524, rs10946398, rs7754840, rs7756992, rs35612982, rs10440833 and rs6931514) were selected based on diabetes-related polymorphisms reported by previous GWAS studies, the NCBI SNP database (https://www.ncbi.nlm. nih.gov/snp/), and minor allele frequencies $>5 \%$ in the 1000 Genomes Project data (http:// www.internationalgenome.org/). The potential function CDKAL1 polymorphisms were estimated by HaploReg version 4.1 (https://pubs.broadinstitute.org/mammals/haploreg/ haploreg.php). Genotyping was performed using Agena MassARRAY system (Agena, San Diego, CA, USA) according to the manufacturer's instructions [16, 17]. The primers for PCR amplification and single base extension were shown in online supplementary Table 1 (for all online suppl. material, see www.karger.com/doi/10.1159/000503175). Cases and controls were randomized during genotyping. Approximately $5 \%$ of the samples were genotyped in duplicate, and the concordance was $100 \%$.

\section{Statistical Analysis}

All data were analyzed by SPSS version 18.0 (SPSS Inc., Chicago, IL, USA) and PLINK software. Student $t$ test or chi-square test was used to compare the difference of characteristics between T2D patients and healthy controls. Demographic and clinical variables were reported as mean (SD) for continuous variables and frequency (percentage) for categorical variables. Hardy-Weinberg equilibrium in controls was determined via a goodness-of-fit $\chi^{2}$ test. ORs and $95 \%$ CIs for multiple inheritance models (allelic, genotype, dominant, recessive and log-additive) were calculated by $\chi^{2}$ and logistic regression analysis to estimate the relationship between CDKAL1 polymorphisms and T2D susceptibility. Bonferroni method was used to correct for multiple comparisons in the overall subjects. Pairwise linkage disequilibrium (LD) and haplotype analyses were analyzed using Haploview (version 4.2) and PLINK software. A two-tailed $p$ value $<0.05$ was considered statistically significant, whereas a value of corrected $p<0.05 /(8 \times 5)$ was considered significant after Bonferroni correction.

\section{Meta-Analysis}

A comprehensive search in PubMed, Embase, and the China National Knowledge Infrastructure databases was conducted using the following search terms: "CDKAL1,"'rs10946398," "rs7754840" and "T2D" up to March of 2019. The articles selected for the subsequent metaanalysis were all published in English in the primary literature. For rs10946398 [18-30] and 
Table 1. Characteristics of patients with T2D and controls

\begin{tabular}{|c|c|c|c|}
\hline Variable & Cases $(n=508)$ & Controls $(n=503)$ & $p$ value \\
\hline Age, years, mean (SD), $n(\%)$ & $59.21(11.90)$ & $59.34(7.62)$ & 0.841 \\
\hline$>59$ & $263(51.8)$ & $265(52.7)$ & \\
\hline$\leq 59$ & $245(48.2)$ & $238(47.3)$ & \\
\hline Gender, male/female, $n(\%)$ & & & 0.712 \\
\hline Male & $277(54.5)$ & $279(55.5)$ & \\
\hline Female & $231(45.5)$ & $224(44.5)$ & \\
\hline \multicolumn{4}{|l|}{ BMI, $\mathrm{kg} / \mathrm{m}^{2}, n(\%)$} \\
\hline$<24$ & $130(25.6)$ & $173(34.4)$ & \\
\hline$\geq 24$ & $187(36.8)$ & $185(36.8)$ & \\
\hline Unavailable & $191(37.6)$ & $145(28.8)$ & \\
\hline \multicolumn{4}{|l|}{ Smoking, $n(\%)$} \\
\hline Yes & $135(26.6)$ & $115(22.9)$ & \\
\hline No & $230(45.3)$ & $188(37.4)$ & \\
\hline Unavailable & $143(28.1)$ & $200(39.8)$ & \\
\hline \multicolumn{4}{|l|}{ Drinking, $n(\%)$} \\
\hline Yes & $68(13.4)$ & $106(21.1)$ & \\
\hline No & $277(54.5)$ & $182(36.2)$ & \\
\hline Unavailable & $163(32.1)$ & 215 (42.7) & \\
\hline Age at diagnosis, years, mean (SD) & $49.05(12.20)$ & & \\
\hline \multicolumn{4}{|l|}{ T2D with retinopathy, $n(\%)$} \\
\hline Yes & $148(29.1)$ & & \\
\hline No & $182(35.8)$ & & \\
\hline Unavailable & $178(35.0)$ & & \\
\hline \multicolumn{4}{|l|}{ Diabetes duration, years, $n(\%)$} \\
\hline$>9$ & $150(29.5)$ & & \\
\hline$\leq 9$ & $185(36.4)$ & & \\
\hline Unavailable & $173(34.1)$ & & \\
\hline Total cholesterol, mmol/L & $4.61(0.88)$ & $4.30(1.63)$ & 0.029 \\
\hline HDL-C, mmol/L & $2.59(0.75)$ & $2.49(1.16)$ & 0.172 \\
\hline LDL-C, mmol/L & $1.12(0.25)$ & $1.50(7.45)$ & 0.378 \\
\hline Serum uric acid, $\mu \mathrm{mol} / \mathrm{L}$ & $6.80(19.8)$ & $5.96(3.38)$ & 0.396 \\
\hline Creatinine, $\mu \mathrm{mol} / \mathrm{L}$ & $67.85(32.08)$ & $65.86(32.18)$ & 0.390 \\
\hline $\mathrm{GFR}, \mathrm{mL} / \mathrm{min}$ & $95.95(13.11)$ & $122.61(35.88)$ & $<0.001$ \\
\hline Fasting blood glucose & $9.95(4.70)$ & & \\
\hline Glycated hemoglobin & $9.30(2.48)$ & & \\
\hline Triglyceride & $2.50(2.26)$ & & \\
\hline Urea & $6.25(3.19)$ & & \\
\hline Creatinine & $68.97(29.49)$ & & \\
\hline Cystatin C & $0.97(2.18)$ & & \\
\hline ALBP & $27.66(52.01)$ & & \\
\hline GFR & $122.61(35.88)$ & & \\
\hline CRP & 1.38 (1.57) & & \\
\hline INS & $18.80(18.65)$ & & \\
\hline 25QWD & 24.69 (15.37) & & \\
\hline UCRP & $0.54(1.28)$ & & \\
\hline RBP & 38.75 (11.14) & & \\
\hline
\end{tabular}

Bold indicate that $p<0.05$ indicates statistical significance.

T2D, type 2 diabetes; BMI, body mass index; HDL-C, high-density lipoprotein cholesterol; LDL-C, low density lipoprotein cholesterol; ALBP, adipocyte lipid-binding protein; GFR, glomerular filtration rate; CRP, C-reactive protein INS, insulin; 25QWD, 25 hydroxy-vitamin D; UCRP, ubiquitin cross-reactive protein; RBP, retinol-binding protein. 
Tian et al.: CDKAL1 rs35612982 Is a Risk Factor of T2D

Table 2. Relationships between the susceptibility to T2D and confounding factors

\begin{tabular}{llcc}
\hline Variable & OR & $95 \% \mathrm{CI}$ & $p$ value \\
\hline Age $(>59$ vs. $\leq 59$ years) & 0.70 & $0.48-1.01$ & 0.056 \\
Gender (male vs. female) & 1.19 & $0.78-1.81$ & 0.427 \\
BMI $\left(>24\right.$ vs. $\leq 24 \mathrm{~kg} / \mathrm{m}^{2}$ ) & 1.57 & $1.09-2.25$ & $\mathbf{0 . 0 1 4}$ \\
Smoking status (yes vs. no) & 1.49 & $0.90-2.47$ & 0.122 \\
Drinking status (yes vs. no) & 0.25 & $0.15-0.42$ & $<\mathbf{0 . 0 0 1}$ \\
\hline
\end{tabular}

Bold values indicate that $p<0.05$ indicates statistical significance. $p$ values were calculated by logistic regression analysis with adjustments for age and gender. T2D, type 2 diabetes; BMI, body mass index.

rs7754840 [20, 22, 29, 31-39], we found 13 and 12 articles respectively. STATA version 11.0 (Stata Corporation, TX, USA) was used to analysis the association of CDKAL1 10946398 and rs7754840 variants with the risk of T2D. The pooled OR in the allele model was assessed by the Z-test, and $p<0.05$ was considered statistical significance. The pooled OR was calculated by a random-effects model if $I^{2}>50 \%$ or $P_{Q}<0.1$, which indicated heterogeneity was significant; otherwise, the pooled OR was assessed by a fixed-effects model [40].

\section{Results}

A total of 508 T2D patients (277 males and 231 females, mean age 59.21 [11.90]) and 214 healthy controls (279 males and 224 females, mean age 59.34 [7.62]) were recruited. Table 1 displayed the clinical and biochemical characteristics of the participants in detail. There was no significant difference in the distribution of gender and age between T2D patients and the healthy controls ( $p=0.841$ and 0.712 respectively). The level of total cholesterol ( $p=$ $0.029)$ and GFR $(p<0.001)$ differed significantly between the T2D group and the normoglycaemic health control group.

Logistic regression analysis was used to assess the relationship between the susceptibility of T2D and confounding factors. We found that BMI $>24 \mathrm{~kg} / \mathrm{m}^{2}$ (OR 1.57, 95\% CI 1.09-2.25, $p=0.014$ ) was significantly associated with a higher risk for T2D, while drinking (OR 0.25 , $95 \%$ CI $0.15-0.42, p<0.001$ ) showed a significant negative association with T2D (Table 2).

The detailed information of candidate SNPs in CDKAL1 was listed in Table 3. The minor allele frequencies of these SNPs were $>5 \%$, and all SNPs were in accordance with HardyWeinberg equilibrium among the controls $(p>0.05)$. Results of allele model showed that 6 SNPs in CDKAL1 were significantly associated with increased T2D risk with overall effects (OR) from 1.34 to 1.43 (rs4712523, OR 1.42, 95\% CI 1.19-1.69, $p=9.44 \times 10^{-5}$; rs4712524, OR 1.38, 95\% CI 1.16-1.65, $p=3.28 \times 10^{-4} ;$ rs10946398, OR 1.43, 95\% CI 1.20-1.71, $p=6.21$ $\times 10^{-5} ;$ rs7754840, OR $1.43,95 \%$ CI $1.20-1.71, p=6.33 \times 10^{-5} ;$ rs35612982, OR 1.34, 95\% CI $1.12-1.60, p=0.0010$; and rs10440833, OR 1.32, 95\% CI 1.11-1.58, $p=0.0018)$. Considering multiple comparisons, we used Bonferroni correction on the results and $p<0.05 /(8 \times 5)$ was considered significant threshold. The significance between CDKAL1 polymorphisms (rs4712523, rs4712524, rs10946398, rs7754840, and rs35612982) still existed after Bonferroni correction.

The genotype frequencies of CDKAL1 polymorphisms were shown in Table 4 and online supplementary Table 2. Among these variants, the genotype frequencies containing "two" risk alleles of rs4712523, rs4712524, rs10946398 and rs7754840 variants were significantly different between case and control groups $(p<0.05)$. After Bonferroni correction, rs 4712523 
Table 3. The information about the candidate SNPs in CDKAL1 and associations with the risk of T2D in the allele model

\begin{tabular}{|c|c|c|c|c|c|c|c|c|}
\hline \multirow[t]{2}{*}{ SNP ID } & \multirow[t]{2}{*}{ Chr: position } & \multirow{2}{*}{$\begin{array}{l}\text { Alleles } \\
\text { (minor/ } \\
\text { major) }\end{array}$} & \multicolumn{2}{|c|}{ Frequency (MAF) } & \multirow{2}{*}{$\begin{array}{l}p \text { value } \\
\text { for HWE }\end{array}$} & \multirow[t]{2}{*}{ OR $(95 \% \mathrm{CI})$} & \multirow[t]{2}{*}{$p$ value } & \multirow[t]{2}{*}{ HaploReg } \\
\hline & & & case & control & & & & \\
\hline rs4712523 & $6: 20657333$ & $\mathrm{G} / \mathrm{A}$ & 0.502 & 0.416 & 0.582 & $1.42(1.19-1.69)$ & $9.44 \times 10^{-5}$ & $\begin{array}{l}\text { Promoter histone marks, Enhancer histone marks, } \\
\text { DNAse, proteins bound, Motifs changed }\end{array}$ \\
\hline rs 4712524 & $6: 20657634$ & $\mathrm{G} / \mathrm{A}$ & 0.502 & 0.422 & 0.268 & $1.38(1.16-1.65)$ & $3.28 \times 10^{-4}$ & $\begin{array}{l}\text { Promoter histone marks, Enhancer histone marks, } \\
\text { DNAse, Motifs changed }\end{array}$ \\
\hline rs10946398 & $6: 20660803$ & $\mathrm{C} / \mathrm{A}$ & 0.499 & 0.410 & 0.783 & $1.43(1.20-1.71)$ & $6.21 \times 10^{-5}$ & DNAse, Motifs changed \\
\hline rs 7754840 & $6: 20661019$ & $\mathrm{C} / \mathrm{G}$ & 0.498 & 0.410 & 0.782 & $1.43(1.20-1.71)$ & $6.33 \times 10^{-5}$ & $\begin{array}{l}\text { Promoter histone marks, Enhancer histone marks, } \\
\text { DNAse, Motifs changed }\end{array}$ \\
\hline rs7756992 & $6: 20679478$ & $\mathrm{~A} / \mathrm{G}$ & 0.451 & 0.487 & 0.788 & $0.87(0.73-1.03)$ & 0.1045 & $\begin{array}{l}\text { Enhancer histone marks, Motifs changed, GRASP } \\
\text { QTL hits }\end{array}$ \\
\hline rs35612982 & $6: 20682391$ & $\mathrm{C} / \mathrm{T}$ & 0.475 & 0.403 & 0.578 & $1.34(1.12-1.60)$ & 0.0010 & Enhancer histone marks, Motifs changed \\
\hline rs10440833 & $6: 20687890$ & $\mathrm{~A} / \mathrm{T}$ & 0.477 & 0.409 & 0.854 & $1.32(1.11-1.58)$ & 0.0018 & Motifs changed \\
\hline rs6931514 & $6: 20703721$ & $\mathrm{~A} / \mathrm{G}$ & 0.453 & 0.489 & 0.929 & $0.87(0.73-1.03)$ & 0.1034 & Enhancer histone marks, Motifs changed \\
\hline
\end{tabular}

Bold values indicate that after Bonferroni correction $(p<0.05 /[8 \times 5])$ means the data is statistically significant.

SNP, single nucleotide polymorphism; T2D, type 2 diabetes; MAF, minor allele frequency; HWE, Hardy-Weinberg equilibrium.

and rs4712524 polymorphisms were associated with the significant susceptibility to T2D under homozygote and additive models (rs4712523: OR 1.97, $p=1.49 \times 10^{-4}$ and OR 1.40, $p=1.43 \times 10^{-4}$; rs4712524, OR 1.85, $p=5.85 \times 10^{-4}$ and OR 1.36, $p=4.85 \times 10^{-4}$; Table 4). Rs10946398 (homozygote: OR 2.03, $p=8.89 \times 10^{-5}$; recessive: OR 1.67, $p=9.91 \times 10^{-4}$; and additive: OR 1.42, $p=9.04 \times 10^{-5}$ ) and rs7754840 (homozygote: OR 2.03, $p=9.07 \times 10^{-5}$; recessive: OR 1.68, $p=9.37 \times 10^{-4}$; and additive: OR 1.42, $p=9.39 \times 10^{-5}$ ) variants had a higher risk for T2D after Bonferroni correction. In addition, rs35612982 (OR 1.78, $p=0.0014$; OR 1.40, $p=0.0121$; OR 1.54, $p=0.0062$ and OR 1.33, $p=0.0015$ ) and rs10440833 (OR 1.75, $p=$ 0.0020 ; OR $1.38, p=0.0190 ;$ OR $1.53, p=0.0070$ and OR $1.31, p=0.0022$ ). SNPs also contributed to the increased T2D risk under multiple genetic models, while the significance was lost when Bonferroni correction was conducted. However, there was no statistically significant association between other 2 SNPs (rs7756992 and rs6931514) and T2D risk ( $p>0.05$, online suppl. Table 2).

We next conducted LD and haplotype analyses of CDKAL1 polymorphisms. Figure 1 revealed the existence of 2 LD blocks in CDKAL1 SNPs (Block 1: rs4712523, rs4712524, rs10946398 and rs7754840; Block 2, rs7756992, rs35612982, rs10440833 and rs6931514). The frequencies of haplotypes in the case and control groups were presented in Table 5. The haplotypes "GGCC" (OR 1.42, $p=9.39 \times 10^{-5}$ ) and "AAAG" (OR 1.36, $p=5.33 \times 10^{-4}$ ) in block 1 and "ATTA" (OR 1.33, $p=0.0013$ ) and "GCAG" (OR 1.55, $p=0.0084$ ) in block 2 were significantly associated with the higher risk of T2D after being adjusted by age and gender.

We further analyzed whether the genotypic effects on T2D risk were dependent on gender and age (online suppl. Table 3). We found that rs4712523, rs4712524, rs10946398, rs7754840, rs35612982 and rs10440833 variants were associated with an increased risk of T2D in both males and females ( $p<0.05)$. Rs4712523, rs10946398, and rs7754840 polymorphisms were at higher risk of developing T2D in subjects at age $>59$ years or at age $\leq 59$ years $(p<0.05)$. Interestingly, associations between CDKAL1 SNPs (rs4712524, rs35612982 and rs10440833) and the increased risk of T2D were found only among participants younger than 59 years of age.

We further examined whether BMI, smoking and drinking status had an effect on the association of CDKAL1 polymorphisms with T2D risk. As shown in online supplementary Table 4, we also found that rs4712523, rs4712524, rs10946398, rs7754840, rs35612982 and rs10440833 variants had increased risk of developing T2D in subgroup with BMI >24 kg/ $\mathrm{m}^{2}$, non-smokers and non-drinking $(p<0.05)$. Moreover, the significant associations between 
Table 4. Relationships between CDKAL1 polymorphisms and T2D risk

\begin{tabular}{|c|c|c|c|c|c|c|}
\hline \multirow[t]{2}{*}{ SNP ID } & \multirow[t]{2}{*}{ Model } & \multirow[t]{2}{*}{ Genotype } & \multirow[t]{2}{*}{ Case } & \multirow[t]{2}{*}{ Control } & \multicolumn{2}{|c|}{ Adjusted by age and gender } \\
\hline & & & & & OR (95\% CI) & $p$ value \\
\hline \multirow[t]{8}{*}{ rs4712523 } & Genotype & AA & 131 & 175 & 1.00 & \\
\hline & & AG & 246 & 238 & $1.38(1.03-1.84)$ & 0.0291 \\
\hline & & GG & 133 & 90 & $1.97(1.39-2.81)$ & $1.49 \times 10^{-4}$ \\
\hline & Dominant & $\mathrm{AA}$ & 131 & 175 & 1.00 & 0.0017 \\
\hline & & AG-GG & 379 & 328 & $1.54(1.18-2.02)$ & \\
\hline & Recessive & $\mathrm{AA}-\mathrm{AG}$ & 377 & 413 & 1.00 & 0.0018 \\
\hline & & GG & 133 & 90 & $1.62(1.20-2.19)$ & \\
\hline & Log-additive & - & - & - & $1.40(1.18-1.67)$ & $1.43 \times 10^{-4}$ \\
\hline \multirow[t]{8}{*}{ rs 4712524} & Genotype & AA & 130 & 171 & 1.00 & \\
\hline & & AG & 246 & 228 & $1.42(1.06-1.90)$ & 0.0189 \\
\hline & & GG & 132 & 94 & $1.85(1.30-2.62)$ & $5.85 \times 10^{-4}$ \\
\hline & Dominant & $\mathrm{AA}$ & 130 & 171 & 1.00 & 0.0018 \\
\hline & & AG-GG & 378 & 322 & $1.54(1.17-2.03)$ & \\
\hline & Recessive & $\mathrm{AA}-\mathrm{AG}$ & 376 & 399 & 1.00 & 0.0090 \\
\hline & & GG & 132 & 94 & $1.49(1.11-2.01)$ & \\
\hline & Log-additive & - & - & - & $1.36(1.15-1.62)$ & $4.85 \times 10^{-4}$ \\
\hline \multirow[t]{8}{*}{ rs10946398 } & Genotype & AA & 132 & 176 & 1.00 & \\
\hline & & $\mathrm{AC}$ & 247 & 240 & 1.37 (1.03-1.83) & 0.0319 \\
\hline & & $\mathrm{CC}$ & 131 & 86 & $2.03(1.43-2.89)$ & $8.89 \times 10^{-5}$ \\
\hline & Dominant & $\mathrm{AA}$ & 132 & 176 & 1.00 & 0.0017 \\
\hline & & AC-CC & 378 & 326 & $1.54(1.18-2.02)$ & \\
\hline & Recessive & $\mathrm{AA}-\mathrm{AC}$ & 379 & 416 & 1.00 & $9.91 \times 10^{-4}$ \\
\hline & & $\mathrm{CC}$ & 131 & 86 & 1.67 (1.23-2.27) & \\
\hline & Log-additive & - & - & - & $1.42(1.19-1.69)$ & $9.04 \times 10^{-5}$ \\
\hline \multirow[t]{8}{*}{ rs7754840 } & Genotype & GG & 133 & 177 & 1.00 & \\
\hline & & GC & 246 & 240 & $1.36(1.02-1.82)$ & 0.0349 \\
\hline & & $\mathrm{CC}$ & 131 & 86 & $2.03(1.42-2.89)$ & $9.07 \times 10^{-5}$ \\
\hline & Dominant & GG & 133 & 177 & 1.00 & 0.0018 \\
\hline & & GC-CC & 377 & 326 & $1.54(1.17-2.01)$ & \\
\hline & Recessive & GG-GC & 379 & 417 & 1.00 & $9.37 \times 10^{-4}$ \\
\hline & & $\mathrm{CC}$ & 131 & 86 & $1.68(1.23-2.28)$ & \\
\hline & Log-additive & - & - & - & 1.42 (1.19-1.69) & $9.39 \times 10^{-5}$ \\
\hline \multirow[t]{8}{*}{ rs35612982 } & Genotype & TT & 147 & 182 & 1.00 & \\
\hline & & $\mathrm{TC}$ & 241 & 235 & $1.27(0.96-1.68)$ & 0.0981 \\
\hline & & $\mathrm{CC}$ & 122 & 85 & $1.78(1.25-2.53)$ & 0.0014 \\
\hline & Dominant & TT & 147 & 182 & 1.00 & 0.0121 \\
\hline & & TC-CC & 363 & 320 & 1.40 (1.08-1.83) & \\
\hline & Recessive & TT-TC & 388 & 417 & 1.00 & 0.0062 \\
\hline & & $\mathrm{CC}$ & 122 & 85 & $1.54(1.13-2.10)$ & \\
\hline & Log-additive & - & - & - & 1.33 (1.11-1.58) & 0.0015 \\
\hline
\end{tabular}


Table 4 (continued)

\begin{tabular}{|c|c|c|c|c|c|c|}
\hline \multirow[t]{2}{*}{ SNP ID } & \multirow[t]{2}{*}{ Model } & \multirow[t]{2}{*}{ Genotype } & \multirow[t]{2}{*}{ Case } & \multirow[t]{2}{*}{ Control } & \multicolumn{2}{|c|}{ Adjusted by age and gender } \\
\hline & & & & & OR $(95 \% \mathrm{CI})$ & $p$ value \\
\hline \multirow[t]{8}{*}{ rs10440833 } & Genotype & TT & 144 & 177 & 1.00 & \\
\hline & & TA & 244 & 241 & $1.24(0.94-1.65)$ & 0.1306 \\
\hline & & $\mathrm{AA}$ & 121 & 85 & $1.75(1.23-2.49)$ & 0.0020 \\
\hline & Dominant & TT & 144 & 177 & 1.00 & 0.0190 \\
\hline & & TA-AA & 365 & 326 & $1.38(1.05-1.79)$ & \\
\hline & Recessive & TT-TA & 388 & 418 & 1.00 & 0.0070 \\
\hline & & $\mathrm{AA}$ & 121 & 85 & $1.53(1.12-2.09)$ & \\
\hline & Log-additive & - & - & - & $1.31(1.10-1.56)$ & 0.0022 \\
\hline
\end{tabular}

Bold values indicate that after Bonferroni correction $(p<0.05 /[8 \times 5])$ means the data is statistically significant. $p$ values were calculated by logistic regression analysis with adjustments for age and gender.

SNP, single nucleotide polymorphism; T2D, type 2 diabetes.

Fig. 1. Haplotype block map for 8 SNPs in the CDKAL1 gene.
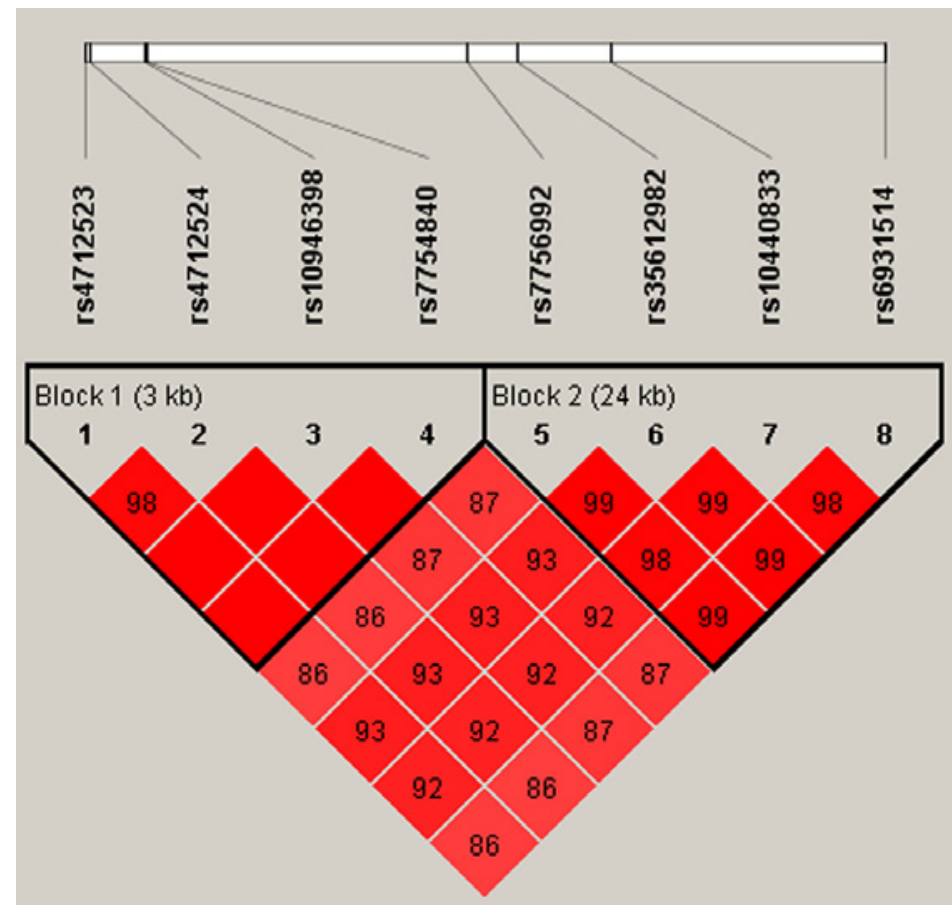

rs35612982 and rs6931514 polymorphisms and T2D susceptibility were observed only in non-smokers $(p<0.05)$.

To evaluate the effect of diabetes duration and retinopathy, T2D patients were divided into 2 groups according to diabetes duration and retinopathy (online suppl. Table 5). Rs4712523 (OR 1.84, $p=0.0281$ ), rs10946398 (OR 1.81, $p=0.0332$ ) and rs7754840 (OR 1.81, $p=0.0332$ ) variants in CDKAL1 were found to be associated with the increased risk of T2D with retinopathy. However, no significant correlation was found in diabetes duration.

The relation between the genotypes of CDKAL1 SNPs and the biochemical indexes in T2D patients was investigated. As shown in Table 6 and online supplementary Table 6, the urea levels for different genotypes of rs7756992 ( $p=0.003), \operatorname{rs35612982}(p=0.015), \operatorname{rs} 10440833(p=$ 
Table 5. Haplotype frequencies in CDKAL1 and their associations with T2D risk

\begin{tabular}{|c|c|c|c|c|c|c|c|c|}
\hline \multirow[t]{2}{*}{ Block } & \multirow[t]{2}{*}{ SNPs } & \multirow[t]{2}{*}{ Haplotype } & \multicolumn{2}{|c|}{ Frequency } & \multicolumn{2}{|l|}{ Crude analysis } & \multicolumn{2}{|c|}{ Adjusted by age and gender } \\
\hline & & & case & control & OR $(95 \% \mathrm{CI})$ & $p$ value & OR ( $95 \% \mathrm{CI})$ & $p$ value \\
\hline \multirow[t]{2}{*}{ Block 1} & rs4712523|rs4712524|rs10946398|rs7754840 & GGCC & 0.498 & 0.410 & $1.42(1.19-1.69)$ & $8.96 \times 10^{-5}$ & $1.42(1.19-1.69)$ & $9.39 \times 10-5$ \\
\hline & rs4712523|rs4712524|rs10946398|rs7754840 & AAAG & 0.503 & 0.424 & $1.36(1.14-1.61)$ & $5.10 \times 10^{-4}$ & $1.36(1.14-1.61)$ & $5.33 \times 10-4$ \\
\hline \multirow[t]{3}{*}{ Block 2} & rs7756992|rs35612982|rs10440833|rs6931514 & ATTA & 0.550 & 0.515 & $1.15(0.97-1.37)$ & 0.1185 & $1.15(0.96-1.36)$ & 0.1203 \\
\hline & rs7756992|rs35612982|rs10440833|rs6931514 & GCAG & 0.473 & 0.399 & $1.33(1.12-1.58)$ & 0.0012 & $1.33(1.12-1.58)$ & 0.0013 \\
\hline & rs7756992|rs35612982|rs10440833|rs6931514 & GTTG & 0.930 & 0.898 & $1.55(1.12-2.15)$ & 0.0085 & $1.55(1.12-2.15)$ & 0.0084 \\
\hline
\end{tabular}

Bold values indicate that $p<0.05$ indicates statistical significance.

The block 1 comprises the 4 closely linked SNPs rs4712523, rs4712524, rs10946398 and rs7754840. The block 2 comprises the 4 closely linked SNPs rs7756992, rs35612982, rs10440833 and rs6931514. $p$ values were calculated using logistic regression analysis with and without adjustment by gender and age. SNP, single nucleotide polymorphism; T2D, type 2 diabetes.

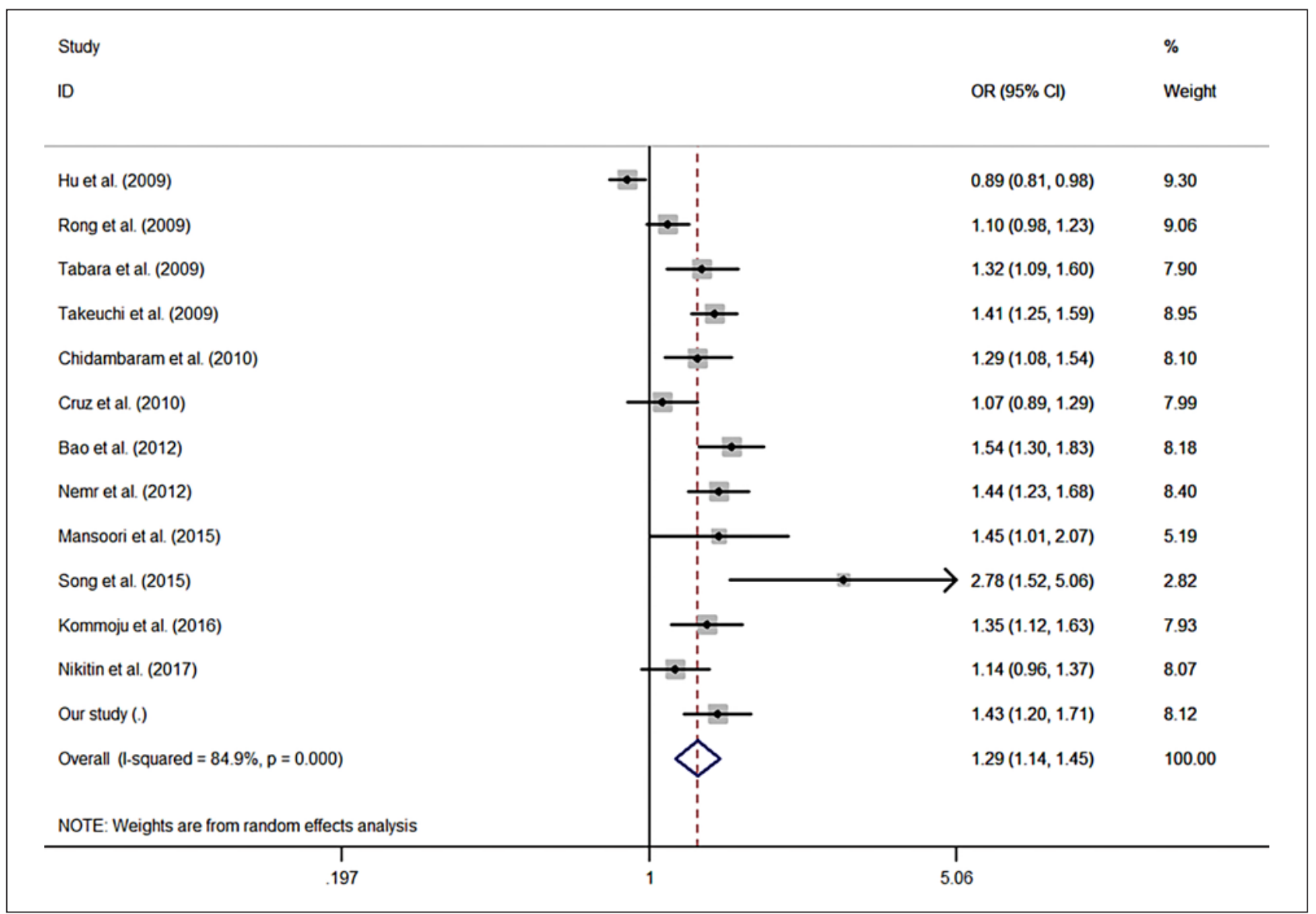

Fig. 2. Forest plot of $C D K A L 1$ rs7754840 polymorphism and T2D susceptibility (allele model). The horizontal lines represent the study-specific ORs and 95\% CIs. The diamond represents the pooled results of OR and $95 \%$ CI.

$0.015)$ and $\mathrm{rs6931514}(p=0.005)$ had a significant difference. A significant association was observed between CDKAL1 rs7756992 and rs6931514 genotypes and the levels of creatinine ( $p=0.045$ and $p=0.037$, respectively). Besides, rs35612982-CT ( $p=0.038)$ and rs10440833-AT $(p=0.044)$ genotypes had a higher insulin level. However, there was no difference in the remaining lipid parameters among the genotypes of the selected SNPs ( $p>0.05$ for all). 
Table 6. Comparisons of clinical characteristics among T2D patients with different genotypes of CDKAL1 SNPs

\begin{tabular}{|c|c|c|c|c|c|c|c|c|}
\hline \multirow[t]{2}{*}{ Characteristics } & \multicolumn{4}{|l|}{ rs7756992 } & \multicolumn{4}{|l|}{ rs35612982 } \\
\hline & $\mathrm{AA}$ & AG & GG & $p$ value & TT & CT & $\mathrm{CC}$ & $p$ value \\
\hline Fasting blood glucose & $10.01(3.76)$ & $9.52(3.98)$ & $10.57(6.04)$ & 0.221 & $10.02(3.51)$ & $9.88(5.05)$ & $10.03(5.22)$ & 0.964 \\
\hline Glycated haemoglobin & $9.54(2.57)$ & $9.13(2.02)$ & $9.39(2.98)$ & 0.496 & $9.52(2.48)$ & $9.23(2.09)$ & $9.16(3.10)$ & 0.593 \\
\hline Total cholesterol & $4.51(1.43)$ & $4.58(1.28)$ & $4.50(1.31)$ & 0.868 & $4.48(1.38)$ & $4.57(1.26)$ & $4.53(1.36)$ & 0.853 \\
\hline Triglyceride & $2.43(2.18)$ & $2.38(1.87)$ & $2.70(2.77)$ & 0.545 & $2.43(2.15)$ & $2.54(2.28)$ & $2.48(2.39)$ & 0.936 \\
\hline LDL-C & $2.60(1.00)$ & $2.74(1.12)$ & $2.47(0.93)$ & 0.068 & $2.62(0.95)$ & $2.71(1.11)$ & $2.46(0.99)$ & 0.160 \\
\hline HDL-C & $1.20(0.60)$ & $1.23(0.61)$ & $1.17(0.52)$ & 0.687 & $1.25(0.66)$ & $1.18(0.60)$ & $1.18(0.42)$ & 0.619 \\
\hline Urea & $7.27(5.55)$ & $5.86(1.80)$ & $6.12(2.48)$ & 0.003 & $6.97(4.93)$ & $6.03(2.06)$ & $5.83(2.23)$ & 0.015 \\
\hline Creatinine & $71.47(31.22)$ & $65.12(17.43)$ & $72.97(39.49)$ & 0.045 & $69.83(28.60)$ & $67.26(29.29)$ & 71.14 (30.87) & 0.529 \\
\hline Cystatin C & $1.47(4.70)$ & $0.82(0.21)$ & $0.88(0.68)$ & 0.136 & 1.29 (3.99) & $0.82(0.22)$ & $0.88(0.77)$ & 0.267 \\
\hline ALBP & $20.24(43.46)$ & 31.67 (57.38) & $26.52(48.50)$ & 0.411 & $29.18(56.25)$ & 31.32 (58.73) & $18.45(24.75)$ & 0.275 \\
\hline GFR & 116.45 (37.76) & 125.09 (35.63) & $122.10(34.25)$ & 0.300 & $119.40(37.95)$ & 123.45 (36.9) & 124.7 (31.63) & 0.612 \\
\hline CRP & $1.29(0.76)$ & $1.53(2.07)$ & $1.18(0.91)$ & 0.234 & $1.30(0.85)$ & $1.50(2.08)$ & $1.23(0.99)$ & 0.433 \\
\hline INS & $15.76(13.08)$ & $21.26(23.50)$ & $16.91(12.01)$ & 0.090 & $16.12(12.64)$ & $21.86(24.07)$ & $16.27(10.63)$ & 0.038 \\
\hline 25QWD & 27.30 (20.01) & $24.60(16.90)$ & $23.02(6.86)$ & 0.344 & 26.08 (17.89) & 24.33 (16.95) & 23.71 (6.69) & 0.672 \\
\hline UCRP & $0.60(1.35)$ & $0.48(1.03)$ & $0.59(1.53)$ & 0.734 & $0.61(1.26)$ & $0.58(1.50)$ & $0.39(0.70)$ & 0.506 \\
\hline RBP & 39.41 (10.59) & 39.70 (11.71) & $36.99(10.6)$ & 0.259 & $39.58(10.61)$ & $38.71(11.63)$ & 37.83 (10.94) & 0.685 \\
\hline \multirow[t]{2}{*}{ Characteristics } & \multicolumn{4}{|l|}{ rs10440833 } & \multicolumn{4}{|l|}{ rs6931514 } \\
\hline & $\mathrm{AA}$ & AT & TT & $p$ value & $\mathrm{AA}$ & $\mathrm{AG}$ & GG & $p$ value \\
\hline Fasting blood glucose & $10.03(5.22)$ & $9.88(5.04)$ & $10.02(3.53)$ & 0.964 & $9.89(3.77)$ & $9.56(3.97)$ & $10.57(6.04)$ & 0.248 \\
\hline Glycated haemoglobin & $9.16(3.10)$ & $9.24(2.09)$ & $9.51(2.49)$ & 0.622 & $9.52(2.54)$ & $9.13(2.03)$ & 9.39 (2.98) & 0.515 \\
\hline Total cholesterol & $4.53(1.36)$ & $4.57(1.26)$ & 4.49 (1.37) & 0.877 & $4.51(1.43)$ & $4.57(1.28)$ & $4.50(1.31)$ & 0.892 \\
\hline Triglyceride & $2.48(2.39)$ & $2.54(2.27)$ & $2.44(2.16)$ & 0.944 & $2.41(2.15)$ & $2.39(1.87)$ & $2.70(2.77)$ & 0.543 \\
\hline LDL-C & $2.45(0.99)$ & $2.70(1.11)$ & $2.63(0.95)$ & 0.149 & $2.61(1.01)$ & $2.74(1.12)$ & $2.47(0.93)$ & 0.072 \\
\hline HDL-C & $1.18(0.42)$ & $1.18(0.60)$ & $1.25(0.67)$ & 0.575 & $1.21(0.60)$ & $1.22(0.61)$ & $1.17(0.52)$ & 0.722 \\
\hline Urea & $5.84(2.24)$ & $6.03(2.05)$ & $6.98(4.95)$ & 0.015 & $7.22(5.49)$ & $5.88(1.8)$ & $6.12(2.48)$ & 0.005 \\
\hline Creatinine & $71.13(31.03)$ & $67.19(29.15)$ & $70.02(28.7)$ & 0.503 & 71.47 (30.87) & $64.89(17.56)$ & 72.97 (39.49) & 0.037 \\
\hline Cystatin C & $0.88(0.77)$ & $0.82(0.22)$ & 1.29 (3.99) & 0.267 & $1.45(4.63)$ & $0.82(0.21)$ & $0.88(0.68)$ & 0.139 \\
\hline ALBP & $18.45(24.75)$ & 31.32 (58.73) & $29.18(56.25)$ & 0.275 & $19.62(42.71)$ & $26.52(48.50)$ & $26.52(48.5)$ & 0.354 \\
\hline GFR & 124.7 (31.63) & 123.45 (36.9) & $119.40(37.95)$ & 0.612 & $115.75(37.32)$ & $126.08(36.13)$ & $122.1(34.25)$ & 0.174 \\
\hline CRP & $1.23(0.99)$ & 1.5 (2.07) & $1.30(0.86)$ & 0.436 & $1.28(0.75)$ & 1.55 (2.08) & $1.18(0.91)$ & 0.196 \\
\hline INS & $16.27(10.63)$ & 21.77 (24) & $16.19(12.70)$ & 0.044 & $15.4(13.01)$ & $21.59(23.52)$ & $16.91(12.01)$ & 0.052 \\
\hline 25QWD & 23.71 (6.69) & 24.24 (16.89) & 26.25 (17.98) & 0.622 & $27.22(19.81)$ & $24.59(16.90)$ & $23.02(6.86)$ & 0.353 \\
\hline UCRP & $0.39(0.70)$ & $0.6(1.51)$ & $0.57(1.22)$ & 0.512 & $0.59(1.34)$ & 0.48 (1.03) & $0.59(1.53)$ & 0.762 \\
\hline RBP & $37.83(10.94)$ & 38.71 (11.63) & $39.58(10.61)$ & 0.685 & $39.54(10.52)$ & $39.56(11.72)$ & $36.99(10.6)$ & 0.274 \\
\hline
\end{tabular}

Bold values indicate that $p<0.05$ indicates statistical significance.

SNP, single nucleotide polymorphism; T2D, type 2 diabetes; LDL-C, low-density lipoprotein cholesterol; HDL-C, high-density lipoprotein cholesterol; ALBP, adipocyte lipid-binding protein; GFR, glomerular filtration rate; CRP, C-reactive protein INS, insulin; 25QWD, 25 hydroxy-vitamin D; UCRP, ubiquitin crossreactive protein; RBP, retinol-binding protein.

Meta-analysis showed that rs7754840 polymorphism conferred to the increased the risk of T2D in the allele model (OR 1.29, 95\% CI 1.14-1.45; Fig. 2). No correlation between 10946398 and T2D risk was found.

\section{Discussion}

In this study, we found significant associations between CDKAL1 polymorphisms (rs4712523, rs4712524, rs10946398, rs7754840, rs35612982 and rs10440833) and T2D risk among the Han population from Northwest China. Specially, this study first provided evidence for the remarkable contribution of CDKAL1 rs35612982 and rs10440833 to T2D susceptibility in the Chinese Han population. More interestingly, we found that genetic variants of CDKAL1 could affect the risk of T2D not only by itself but also by associating with age, BMI and the status of smoking and drinking. Besides, rs35612982-CTand rs10440833-ATgenotypes had a higher insulin level.

CDKAL1 gene is regarded as T2D susceptibility gene involved in glucose regulation and insulin secretion/action [41]. CDKAL1 variants were related with defects in proinsulin conversion and insulin response upon glucose stimulation [42]. Several studies have provided 


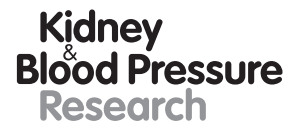

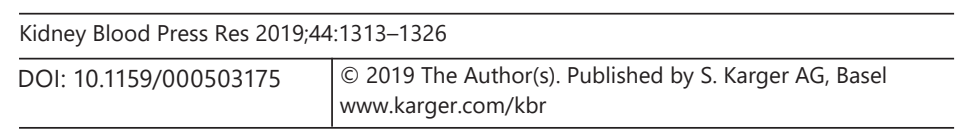

Tian et al.: CDKAL1 rs35612982 Is a Risk Factor of T2D

evidence for the significant contribution of CDKAL1 polymorphisms to T2D risk [35, 43, 44]. Consistent with previous reports, CDKAL1 variants (rs4712523, rs4712524, rs10946398, rs7754840) were associated with T2D susceptibility in the Chinese Han population. Moreover, our results first found that rs35612982 and rs10440833 polymorphisms conferred to the increased risk of T2D among the Chinese Han population, especially rs35612982 polymorphism that has not been reported. This result suggests that the CDKAL1rs35612982 variant might play an important role in the pathogenesis of T2D. Previously, Lu et al. [43] suggested that rs6931514 and rs7756992 were associated with increased T2D risk in Chinese populations. However, there was no association of rs6931514 and rs7756992 with the risk of T2D in our study. A global meta-analysis also revealed that no association for the SNP rs7756992 was found in the Asian population [45]. Such inconsistencies in these reports may result from different environmental conditions or insufficient sample size.

Genetic and environmental factors are interrelated and contribute to the development of T2D. Age, obesity, and unhealthy lifestyle identify those individuals at highest risk of T2D [46]. Interestingly, we found that rs4712524, rs35612982 and rs10440833 variants contributed the increased T2D risk at age $\leq 59$ not $>59$ years, suggesting that the risk association might be age dependent. Overweight and obesity (defined by BMI) is a known risk factor for T2D [47]. We found that BMI $>24 \mathrm{~kg} / \mathrm{m}^{2}$ was associated with increased risk of T2D. Stratified by BMI, we found that CDKAL1 polymorphisms (rs4712523, rs4712524, rs10946398, rs7754840, rs35612982 and rs10440833) were associated with the increased susceptibility to T2D in the overweight/obese (BMI $>24 \mathrm{~kg} / \mathrm{m}^{2}$ ) population. Smoking and drinking (especially heavy alcohol consumption) are known risk factors for diabetes. Smoking increases the risk of T2D by 30-40\% for active smokers compared to non-smokers [48]. It has been found that cigarette smoking and alcohol consumption are related to glycaemic control and insulin resistance $[49,50]$. However, drinking might have a reduced T2D risk, while smoking had no association with T2D in our study. In addition, our results revealed that CDKAL1 polymorphisms increased the risk of T2D among those non-smokers and non-drinkers. The effect of smoking and drinking on the association between CDKAL1 polymorphisms and the susceptibility of T2D are required to validate the results in larger populations and in laboratory-based functional experiments. However, the limitations of the present study should not be ignored. First, the subjects were enrolled from identical hospitals; therefore, they may not be representative of the general population. Second, the potential function of these SNPs in the aetiology of T2D was still unknown; thus, genetic and functional analyses were urgently required to reveal the precise role of these polymorphisms in T2D.

\section{Conclusions}

In conclusion, the present study identified the CDKAL1 rs35612982 (C/T) polymorphism, as a novel polymorphism, associated with T2D in the Han population from Northwest China. Our study might help to enhance the understanding of CDKAL1 gene mutations in the pathogenesis of T2D. Further studies are needed to evaluate the functional and epidemiological importance of the rs35612982 polymorphism in T2D.

\section{Acknowledgements}

We thank the individuals who participated in this study. We also thank the clinicians and hospital staff who contributed to the sample and data collection for this study. 


\section{Kidney \\ Blood Pressure Research}

\begin{tabular}{l|l}
\hline Kidney Blood Press Res 2019:44:1313-1326 \\
\hline DOI: 10.1159/000503175 & $\begin{array}{l}\text { @ 2019 The Author(s). Published by S. Karger AG, Basel } \\
\text { www.karger.com/kbr }\end{array}$ \\
\hline
\end{tabular}

Tian et al.: CDKAL1 rs35612982 Is a Risk Factor of T2D

\section{Statement of Ethics}

This case-control study was carried out with the approval of the Ethics Committee of the First Affiliated Hospital of Xi' an Jiaotong University and in accordance with the guidelines of the Declaration of Helsinki. All participants were informed about the purpose of this study and signed a written informed consent.

\section{Disclosure Statement}

The authors declare that they have no conflict of interest.

\section{Funding Sources}

This work was supported by Key Research and Development Plan from the Shaanxi Provincial Science (2018SF-156) and Social Development Science and Technology Public Relations Project from the Shaanxi Provincial Science (2016SF-314).

\section{References}

1 Nolan CJ, Damm P, Prentki M. Type 2 diabetes across generations: from pathophysiology to prevention and management. Lancet. 2011 Jul;378(9786):169-81.

2 Salunkhe VA, Veluthakal R, Kahn SE, Thurmond DC. Novel approaches to restore beta cell function in prediabetes and type 2 diabetes. Diabetologia. 2018 Sep;61(9):1895-901.

3 Yang W, Lu J, Weng J, Jia W, Ji L, Xiao J, et al.; China National Diabetes and Metabolic Disorders Study Group. Prevalence of diabetes among men and women in China. N Engl J Med. 2010 Mar;362(12):1090-101.

4 Wu Y, Ding Y, Tanaka Y, Zhang W. Risk factors contributing to type 2 diabetes and recent advances in the treatment and prevention. Int J Med Sci. 2014 Sep;11(11):1185-200.

5 Scott RA, Scott LJ, Mägi R, Marullo L, Gaulton KJ, Kaakinen M, et al. An Expanded Genome-Wide Association Study of Type 2 Diabetes in Europeans. Diabetes. 2017 Nov;66(11):2888-902.

6 Zhao W, Rasheed A, Tikkanen E, Lee JJ, Butterworth AS, Howson JMM, et al. Identification of new susceptibility loci for type 2 diabetes and shared etiological pathways with coronary heart disease. Nat Genet. 2017 Oct; 49(10):1450-7.

7 Ubeda M, Rukstalis JM, Habener JF. Inhibition of cyclin-dependent kinase 5 activity protects pancreatic beta cells from glucotoxicity. J Biol Chem. 2006 Sep;281(39):28858-64.

8 Ching YP, Pang AS, Lam WH, Qi RZ, Wang JH. Identification of a neuronal Cdk5 activator-binding protein as Cdk5 inhibitor. J Biol Chem. 2002 May;277(18):15237-40.

9 Zeggini E, Weedon MN, Lindgren CM, Frayling TM, Elliott KS, Lango H, et al.; Wellcome Trust Case Control Consortium (WTCCC). Replication of genome-wide association signals in UK samples reveals risk loci for type 2 diabetes. Science. 2007 Jun;316(5829):1336-41.

10 Pascoe L, Tura A, Patel SK, Ibrahim IM, Ferrannini E, Zeggini E, et al.; RISC Consortium; U.K. Type 2 Diabetes Genetics Consortium. Common variants of the novel type 2 diabetes genes CDKAL1 and HHEX/IDE are associated with decreased pancreatic beta-cell function. Diabetes. 2007 Dec;56(12):3101-4.

11 Steinthorsdottir V, Thorleifsson G, Reynisdottir I, Benediktsson R, Jonsdottir T, Walters GB, et al. A variant in CDKAL1 influences insulin response and risk of type 2 diabetes. Nat Genet. 2007 Jun;39(6):770-5.

12 Scott LJ, Mohlke KL, Bonnycastle LL, Willer CJ, Li Y, Duren WL, et al. A genome-wide association study of type 2 diabetes in Finns detects multiple susceptibility variants. Science. 2007 Jun;316(5829):1341-5.

13 Saxena R, Voight BF, Lyssenko V, Burtt NP, de Bakker PI, Chen H, et al.; Diabetes Genetics Initiative of Broad Institute of Harvard and MIT, Lund University, and Novartis Institutes of BioMedical Research. Genome-wide association analysis identifies loci for type 2 diabetes and triglyceride levels. Science. 2007 Jun;316(5829):1331-6.

14 Li YY, Wang LS, Lu XZ, Yang ZJ, Wang XM, Zhou CW, et al. CDKAL1 gene rs7756992 A/G polymorphism and type 2 diabetes mellitus: a meta-analysis of 62,567 subjects. Sci Rep. 2013 Nov;3(1):3131.

15 Alberti KG, Zimmet PZ. Definition, diagnosis and classification of diabetes mellitus and its complications. Part 1: diagnosis and classification of diabetes mellitus provisional report of a WHO consultation. Diabet Med. 1998 Jul;15(7):539-53.

16 Gabriel S, Ziaugra L, Tabbaa D. SNP genotyping using the Sequenom MassARRAY iPLEX platform. Curr Protoc Hum Genet. 2009 Jan;Chapter 2:Unit 2.12. 


\begin{tabular}{l|l}
\hline \multicolumn{2}{l}{ Kidney Blood Press Res 2019;44:1313-1326 } \\
\hline DOI: 10.1159/000503175 & $\begin{array}{l}\text { @ 2019 The Author(s). Published by S. Karger AG, Basel } \\
\text { www.karger.com/kbr }\end{array}$ \\
\hline
\end{tabular}

Tian et al.: CDKAL1 rs35612982 Is a Risk Factor of T2D

17 Thomas RK, Baker AC, Debiasi RM, Winckler W, Laframboise T, Lin WM, et al. High-throughput oncogene mutation profiling in human cancer. Nat Genet. 2007 Mar;39(3):347-51.

18 Liu Y, Yu L, Zhang D, Chen Z, Zhou DZ, Zhao T, et al. Positive association between variations in CDKAL1 and type 2 diabetes in Han Chinese individuals. Diabetologia. 2008 Nov;51(11):2134-7.

19 Wu Y, Li H, Loos RJ, Yu Z, Ye X, Chen L, et al. Common variants in CDKAL1, CDKN2A/B, IGF2BP2, SLC30A8, and HHEX/IDE genes are associated with type 2 diabetes and impaired fasting glucose in a Chinese Han population. Diabetes. 2008 0ct;57(10):2834-42.

20 Hu C, Zhang R, Wang C, Wang J, Ma X, Lu J, et al. PPARG, KCNJ11, CDKAL1, CDKN2A-CDKN2B, IDE-KIF11-HHEX, IGF2BP2 and SLC30A8 are associated with type 2 diabetes in a Chinese population. PLoS One. 2009 Oct; 4(10):e7643.

21 Chauhan G, Spurgeon CJ, Tabassum R, Bhaskar S, Kulkarni SR, Mahajan A, et al. Impact of common variants of PPARG, KCNJ11, TCF7L2, SLC30A8, HHEX, CDKN2A, IGF2BP2, and CDKAL1 on the risk of type 2 diabetes in 5,164 Indians. Diabetes. 2010 Aug;59(8):2068-74.

22 Cruz M, Valladares-Salgado A, Garcia-Mena J, Ross K, Edwards M, Angeles-Martinez J, et al. Candidate gene association study conditioning on individual ancestry in patients with type 2 diabetes and metabolic syndrome from Mexico City. Diabetes Metab Res Rev. 2010 May;26(4):261-70.

23 Han X, Luo Y, Ren Q, Zhang X, Wang F, Sun X, et al. Implication of genetic variants near SLC30A8, HHEX, CDKAL1, CDKN2A/B, IGF2BP2, FTO, TCF2, KCNQ1, and WFS1 in type 2 diabetes in a Chinese population. BMC Med Genet. 2010 May;11(1):81.

24 Lin Y, Li P, Cai L, Zhang B, Tang X, Zhang X, et al. Association study of genetic variants in eight genes/loci with type 2 diabetes in a Han Chinese population. BMC Med Genet. 2010 Jun;11(1):97.

25 Wen J, Rönn T, Olsson A, Yang Z, Lu B, Du Y, et al. Investigation of type 2 diabetes risk alleles support CDKN2A/B, CDKAL1, and TCF7L2 as susceptibility genes in a Han Chinese cohort. PLoS One. 2010 Feb;5(2):e9153.

26 Ryoo H, Woo J, Kim Y, Lee C. Heterogeneity of genetic associations of CDKAL1 and HHEX with susceptibility of type 2 diabetes mellitus by gender. Eur J Hum Genet. 2011 Jun;19(6):672-5.

27 Cooke JN, Ng MC, Palmer ND, An SS, Hester JM, Freedman BI, et al. Genetic risk assessment of type 2 diabetesassociated polymorphisms in African Americans. Diabetes Care. 2012 Feb;35(2):287-92.

28 Al-Sinani S, Woodhouse N, Al-Mamari A, Al-Shafie O, Al-Shafaee M, Al-Yahyaee S, et al. Association of gene variants with susceptibility to type 2 diabetes among Omanis. World J Diabetes. 2015 Mar;6(2):358-66.

29 Nikitin AG, Potapov VY, Brovkina OI, Koksharova EO, Khodyrev DS, Philippov YI, et al. Association of polymorphic markers of genes FTO, KCNJ11, CDKAL1, SLC30A8, and CDKN2B with type 2 diabetes mellitus in the Russian population. PeerJ. 2017 Jul;5:e3414.

30 Nfor ON, Wu MF, Lee CT, Wang L, Liu WH, Tantoh DM, et al. Body mass index modulates the association between CDKAL1 rs10946398 variant and type 2 diabetes among Taiwanese women. Sci Rep. 2018 Sep;8(1): 13235.

31 Rong R, Hanson RL, Ortiz D, Wiedrich C, Kobes S, Knowler WC, et al. Association analysis of variation in/near FTO, CDKAL1, SLC30A8, HHEX, EXT2, IGF2BP2, LOC387761, and CDKN2B with type 2 diabetes and related quantitative traits in Pima Indians. Diabetes. 2009 Feb;58(2):478-88.

32 Tabara Y, Osawa H, Kawamoto R, Onuma H, Shimizu I, Miki T, et al. Replication study of candidate genes associated with type 2 diabetes based on genome-wide screening. Diabetes. 2009 Feb;58(2):493-8.

33 Takeuchi F, Serizawa M, Yamamoto K, Fujisawa T, Nakashima E, Ohnaka K, et al. Confirmation of multiple risk Loci and genetic impacts by a genome-wide association study of type 2 diabetes in the Japanese population. Diabetes. 2009 Jul;58(7):1690-9.

34 Chidambaram M, Radha V, Mohan V. Replication of recently described type 2 diabetes gene variants in a South Indian population. Metabolism. 2010 Dec;59(12):1760-6.

35 Bao XY, Peng B, Yang MS. Replication study of novel risk variants in six genes with type 2 diabetes and related quantitative traits in the Han Chinese lean individuals. Mol Biol Rep. 2012 Mar;39(3):2447-54.

36 Nemr R, Almawi AW, Echtay A, Sater MS, Daher HS, Almawi WY. Replication study of common variants in CDKAL1 and CDKN2A/2B genes associated with type 2 diabetes in Lebanese Arab population. Diabetes Res Clin Pract. 2012 Feb;95(2):e37-40.

37 Mansoori Y, Daraei A, Naghizadeh MM, Salehi R. Significance of a common variant in the CDKAL1 gene with susceptibility to type 2 diabetes mellitus in Iranian population. Adv Biomed Res. 2015 Feb;4(1):45.

38 Song M, Zhao F, Ran L, Dolikun M, Wu L, Ge S, et al. The Uyghur population and genetic susceptibility to type 2 diabetes: potential role for variants in CDKAL1, JAZF1, and IGF1 genes. OMICS. 2015 Apr;19(4):230-7.

39 Kommoju UJ, Samy SK, Maruda J, Irgam K, Kotla JP, Velaga L, et al. Association of CDKAL1, CDKN2A/B \& HHEX gene polymorphisms with type 2 diabetes mellitus in the population of Hyderabad, India. Indian J Med Res. 2016 Apr;143(4):455-63.

40 Neupane B, Beyene J. Multivariate Meta-Analysis of Genetic Association Studies: A Simulation Study. PLoS One. 2015 Jul;10(7):e0133243.

41 Goodarzi MO, Guo X, Cui J, Jones MR, Haritunians T, Xiang AH, et al. Systematic evaluation of validated type 2 diabetes and glycaemic trait loci for association with insulin clearance. Diabetologia. 2013 Jun;56(6):128290.

42 Ruchat SM, Elks CE, Loos RJ, Vohl MC, Weisnagel SJ, Rankinen T, et al. Association between insulin secretion, insulin sensitivity and type 2 diabetes susceptibility variants identified in genome-wide association studies. Acta Diabetol. 2009 Sep;46(3):217-26. 
43 Lu F, Qian Y, Li H, Dong M, Lin Y, Du J, et al. Genetic variants on chromosome 6p21.1 and 6p22.3 are associated with type 2 diabetes risk: a case-control study in Han Chinese. J Hum Genet. 2012 May;57(5):320-5.

44 Liu NJ, Xiong Q, Wu HH, Li YL, Yang Z, Tao XM, et al. The association analysis polymorphism of CDKAL1 and diabetic retinopathy in Chinese Han population. Int J Ophthalmol. 2016 May;9(5):707-12.

45 Dehwah MA, Wang M, Huang QY. CDKAL1 and type 2 diabetes: a global meta-analysis. Genet Mol Res. 2010 Jun;9(2):1109-20.

46 Fletcher B, Gulanick M, Lamendola C. Risk factors for type 2 diabetes mellitus. J Cardiovasc Nurs. 2002 Jan; 16(2):17-23.

47 Ganz ML, Wintfeld N, Li Q, Alas V, Langer J, Hammer M. The association of body mass index with the risk of type 2 diabetes: a case-control study nested in an electronic health records system in the United States. Diabetol Metab Syndr. 2014 Apr;6(1):50.

48 Maddatu J, Anderson-Baucum E, Evans-Molina C. Smoking and the risk of type 2 diabetes. Transl Res. 2017 Jun;184:101-7.

49 Ohkuma T, Iwase M, Fujii H, Kaizu S, Ide H, Jodai T, et al. Dose- and time-dependent association of smoking and its cessation with glycemic control and insulin resistance in male patients with type 2 diabetes mellitus: the Fukuoka Diabetes Registry. PLoS One. 2015 Mar;10(3):e0122023.

50 Steiner JL, Crowell KT, Lang CH. Impact of Alcohol on Glycemic Control and Insulin Action. Biomolecules. 2015 Sep;5(4):2223-46. 